\title{
El acervo escolar: manual de organización y cuidados básicos
}

\section{The school acquis organization and basic care manual}

\author{
lomar Barbosa Zaia ${ }^{5}$ \\ Enoc J essé Castro García \\ Traducción y Resumen ${ }^{6}$
}

\section{Resumen}

Con el objetivo de ofrecer orientaciones técnicas de higienización, acondicionamiento (conservación preventiva) y pequeños restauros para la preservación de la documentación representativa de la historia de la escuela, fue lanzado en el 2004 el Manual El Acervo Escolar: organización y cuidados básicos, como resultado del trabajo desarrollado por la archivista. Iomar Zaia junto al Centro de Memoria de la Educación de la Facultad de Educación de la USP. Debido al interés cada vez mayor mostrado por investigadores y por equipos escolares en relación a los Archivos Escolares - tanto entorno de la búsqueda de técnicas más actualizadas de conservación documental como de discusiones teóricas colocadas por el campo de la Historia de la Educación-, se ofrece una guía para que las escuelas y su equipo encuentren soporte para el trabajo de conservación documental de los Archivos Escolares, fundamental para ampliar las posibilidades de comprender la historia de la escuela de ayer y hoy.

\footnotetext{
${ }^{5}$ Universidad de São Paulo, Facultad de Educación

${ }^{6}$ Profesor de Matemáticas con Orientación en Física en el Grado de Licenciatura. Honduras, C.A. belza34@hotmail.com
} 
Palabras Clave: Acervo escolar, archivística, memoria escolar, conservación documental.

Abstrac: The purpose of this study was offering sanitation techniques, conditioning (precautionary preservation) and little restoration for preserving the most important documentation of the school's history. In 2004 was published " El Acervo Escolar Manual": organization and documents basic cares which work was done by the filing-clerk lomar Zaia together with El Centro de Memoria de la Educación de la Facultad de Educación de Ia USP. Due to the great interest showed by researchers and scholar teams about how to keep the scholar records, also there was an interest that has to do with update documental preservation searching techniques as theoretical discussions suggested by the Education History field. For solving this issue it was provided a guide to the schools that allowed their teams to find support for doing the scholar records documental preservation. This work was decisive for extending the possibilities of understanding of the school history from then and now.

Key words: Scholar heritage, archival, scholar memory, documental preservation.

\section{La disciplina archivística}

\section{Rápido histórico}

En la organización de un acervo documental, es necesario mucho más que el sentido común. Es necesario conocer los fundamentos de la disciplina que desde el siglo XIX se viene preocupando con la organización de archivos.

Inicialmente, la historia de la archivística puede ser vista desde las primeras civilizaciones. Sin embargo, esto sólo sería posible si el objetivo de este texto explorara únicamente la historia de esta área. Cabe resaltar que el momento relevante para mi propuesta está bien definido: se trata de finales del siglo XIX.

En ese período, más precisamente en 1898, todo un proceso de 
organización de la disciplina archivística se estaba concretizando. Y el esfuerzo que sintetizaba los deseos iniciales de esa disciplina fue la elaboración del Manual de los Archivistas Holandeses.

Arreglo documental.

Ese trabajo representa un avance en la teorización archivística que se inició en la Revolución Francesa con la idea de concretización de los archivos del Estado en grandes depósitos y culminó a finales del siglo XIX con la proliferación de los archivos como lugares de memoria, o sea, fueron creados locales definidos para los:

Archivos donde serían incorporados documentos de interés histórico que no nacen de una forma natural, pero sí, de servicios especializados que tiene como función principal hacer que la información sea accesible al público.

En ese momento la memoria pierde espacio para hacerlo histórico, y el documento gana importancia por su valor de prueba y de testimonio.

De esa manera, nace una política de protección y preservación de acervos, se fundan Asociaciones, se establecen leyes, otros manuales son escritos y, principalmente, se organizan archivos de acuerdo con los principios archivísticos.

Con el aumento del volumen de documentos, provocado por la nueva política de protección de la cual habla el autor anteriormente, surge una nueva preocupación. Entre las dos grandes Guerras Mundiales, nace la problemática en torno de la cuestión de evaluación de los documentos que estaban siendo guardados por todas las instituciones, consecuencia de toda la acumulación generada por la política de protección hasta entonces desarrollada por los países.

Con eso, los mismos grupos que antes se esforzaban por proteger documentos, ahora se empeñaban en encontrar justificaciones para destruirlos. Una nueva ola en el área de la archivística comenzaba: para Inglaterra, por ejemplo, "la tendencia tradicional era la de destruir lo que no tenía interés del punto de vista legal, histórico, 
Iomar Barbosa Zaia

estadístico, económico o para cualquier fin oficial".

Ya los al emanes preferían crear tres regl as básicas para la evaluación. "Tales reglas establecían como parámetros esenciales de evaluación la edad, el contenido y la posición jerárquica de la identidad productora, en el ámbito de la administración".

Vale destacar que fue en EUA que ocurrió la síntesis de esas dos concepciones (alemana e inglesa). A partir de los estudios del bibliotecario Teodoro Schellenberg, surgió la base para una política de evaluación que sería utilizada en los años siguientes por muchos países. Según Malheiro, fue Schellenberg quien elaboró la teoría de un valor primario para la entidad productora y de un valor secundario del documento para la investigación. "así, el objetivo era conservar el máximo de información posible en un mínimo de documentos".

El primer documento de ley que trata del asunto es el decreto $\mathrm{n}$ 200, de 22 de enero de 1962, del Ministerio de Educación y Cultura/ MEC-DEM, que autoriza la "reducción del volumen de los archivos con el expurgo de papeles de valor transitorio e inútiles a la conservación y ordenación de los documentos esenciales".

Pero, ¿qué fue considerado documentos esenciales?

Según el decreto, fueron considerados documentos esenciales las actas generales de exámenes de admisión, las actas finales, las actas de exámenes del segundo período, de exámenes especiales, revalidación, adaptación, fichas de transferencia, de notas y otros documentos que registraron el desempeño del alumno, que prueban la realización de sus actividades. Básicamente podemos entender como documentos preservados, todos aquellos que pueden ser encontrados en el proceso/prontuario del alumno. El resto de documentos, como diarios de clases, recortes de periódicos sobre la Escuela, cuadernos de los alumnos, diarios de profesores, entre otros, eran considerados no esenciales, pudiendo ser quemados.

En la década de 1970 la legislación tenía previsto una nueva política de descarte, basada en la reducción de los documentos. En la indicación no 72 del Dictamen ํo 16 del 27 de enero de 1976, está 
propuesto que sean adoptados algunos procedimientos referentes a la eliminación de los documentos escolares. El primero de ellos se basaba en sustitución de los protectores y conservación de los papeles originales por reducciones.

Finalmente, podemos percibir que la política brasileña, cuando se trata de evaluación documental, ha sido favorable a que se eliminen de las escuelas la gran cantidad de papeles viejos, que no contribuyen en nada para el desarrollo educacional de Brasil.

Como decía la propia legislación que trataba del asunto, "la conservación y protección del archivo muerto ocupa espacio que, con la acumulación a lo largo de los años, tiende a alcanzar proporciones indeseables (Dictamen no 342/78-CFE/ MEC).

\section{Principios básicos}

De acuerdo con la archivística, existen tres principios básicos de mucha importancia para toda organización, los cuales fueron tomados en cuenta en los trabajos desarrollados en el MEMO.

Principio de la territorialidad

El trabajo: Los fundamentos de la disciplina archivística define este principio como: "[...] el principio según el cual los archivos públicos, propios de un territorio, siguen el destino de este último".

En el caso de la Escuela de Aplicación, desde que comenzó como proyecto el montaje del Centro de Memoria de la Escuela surgió la importancia del respeto a ese principio. Conversando con la dirección de la escuela, vimos que los documentos de la institución deberían ser organizados y mantenidos bajo sus cuidados.

Otra alternativa sería llevarlos para el CMEFEUSP. Sin embargo, si la idea que está detrás de ese principio procede, no permite archivística en sí, es decir, que si los documentos fueran generados dentro de una institución que responde a los objetivos que propone, tales documentos reflejan cuánto dicha institución se empeñó - y se empeña - en el desarrollo de sus atribuciones. Así, retirar la 
documentación de su contexto es fragmentar una posible interpretación en el trabajo de preservación de la memoria institucional.

Todavía, no podríamos olvidarnos de casos en que la institución deja de existir y la documentación acumulada termina en un destino diferente. Es en estos casos que se busca mantener junto el acervo de la institución.

\section{Principio de procedencia}

Debido a los términos tomados en cuenta en el primer principio en nuestros trabajos, este segundo nos fue de fácil aplicación. Consiste "en dejar agrupados, sin mezclarlos con los otros, los archivos provenientes de una administración, de un establecimiento o de una persona en particular".

De esa manera, al mantener los documentos en la misma institución, evitamos mezclarlos con otros archivos, asegurando así el sustento del conjunto documental orgánico.

Principio del abordaje de las tres edades

Este principio, que se relaciona con el abordaje de las tres edades, se "asienta en las etapas de vida de los documentos".

La definición de estas tres edades o fases puede ser sintetizada y entendida de la siguiente forma:

El primer conjunto de documentos reunidos, que corresponde a los documentos que sirven regularmente para la administración de la institución, está en edad activa; el segundo, correspondiente a aquellos utilizados ocasionalmente, está en edad semi-activa; y el tercero, que corresponde al conjunto de documentos conservados de modo permanente, está en edad inactiva.

Esas tres edades son conocidas también como fase corriente, fase intermediaria y fase permanente. En la Escuela de Aplicación, actualmente, se puede observar que se toman en cuenta las tres 
fases. En el MEMO, utilizamos la palabra Archivo en lugar de fases o edades. Además, podemos observar que se encuentran en ambientes diferentes, pues cuando un documento pasa de una edad a otra, se debe evaluar para recibir un tratamiento de acuerdo a su destino. Esa evaluación se deberá hacer, aun en su fase corriente, por un equipo formado por representantes de las funciones y actividades escolares, y determinará si el documento ha de ir al Archivo Intermediario, Archivo Permanente o si debe ser descartado/ eliminado. Si el documento va para el Intermediario, al terminar el plazo previsto aun en la evaluación, será encaminado al Archivo Permanente o será descartado. Así el uso de los términos Archivo Corriente, Archivo Intermediario y Archivo Permanente involucra todas las actividades y la creación de instrumentos que deberán auxiliar en el tratamiento del documento los empleados de la institución.

\section{La Organización}

La distribución de ambientes en el Centro de Memoria escolar

La distribución de los espacios en el Centro de Memoria fue hecha para integrar actividades desarrolladas en un ambiente de investigación, por un Archivo Intermediario, un Archivo Permanente y un Centro de Documentación y Memoria.

La idea para esa disposición de los espacios de un Centro de Documentación y Memoria Escolar nació de la necesidad de restringir el acceso de alumnos e investigadores al espacio destinado a la investigación en el MEMO y delimitar los espacios para cada actividad, auxiliando, de esta manera, en la conservación de la organización, así como en el acceso a la información.

El espacio destinado al Centro de Memoria de la Escuela fue dividido en tres ambientes, que fueron subdivididos de acuerdo a las fases documentales y, consecuentemente, las actividades ligadas a ellas.

Como se trata de un trabajo que pretende involucrar a los alumnos en todas las fases de organización del Centro, se prestó atención a la selección de colores significativos para identificar los tres 
ambientes. Se eligieron los colores del semáforo: el verde representa un espacio donde todos pueden transitar libremente; el amarillo representa un espacio que requiere mayor atención, pues se trata de un área de trabajo donde es necesario la autorización previa para entrar; el rojo representa un espacio donde sólo entran responsables por la institución u organización (archivistas o empleados de la secretaría).

De esta manera, al entrar en el MEMO, el investigador tendrá un espacio destinado para consultar los instrumentos de investigación (sean bases de datos, inventarios, guías, etc.). En ese espacio, el ambiente verde, siempre tendrá una pequeña exposición de piezas, trabajos y cuadros fotográficos que se encontraron durante la organización del Archivo o donados por empleados de la Escuela, ex alumnos y ex profesores.

Al exceder ese primer espacio, el consultante habrá llegado al ambiente amarillo, reservado para la limpieza, recuperación y acondicionamiento de documentos. Los archivos de acero, muy utilizados en las escuelas para protección de documentos, pueden ser conservados en ese segundo espacio, albergando la documentación en su fase Intermediaria. Por otra parte, la documentación sólo podrá ser manejada por el equipo de empleados de la Secretaría o por el responsable del centro de Documentación y Memoria.

Si el Centro de Memoria tuviera un baño, éste deberá ser usado exclusivamente por el empleado o por el equipo responsable, manteniéndose siempre la puerta cerrada. Como es un espacio demasiado húmedo, se debe mantener un deshumidificador próximo a este espacio.

Otro espacio que puede estar próximo al espacio amarillo, es la reserva técnica del Centro de Memoria, que tiene como objetivo proteger los materiales de limpieza, restauro y acondicionamiento.

El tercer ambiente es el espacio reservado a la protección de documentos en su fase permanente o histórica y está ocupado únicamente por el archivo corredizo o armarios de protección de la documentación de carácter permanente. La organización de esos 
ambientes (o sectores) en el MEMO está simbolizada por tres placas con su identificación en los colores mencionados anteriormente.

Todos los muebles y aparatos del Centro recibieron etiquetas en el color correspondiente al grupo de actividades desarrolladas en uno de los tres ambientes, lo que significa que pertenecen a una determinada actividad a ser desarrollada en el espacio preestablecido. Con eso, se pretende evitar que los materiales sean transportados de un lugar a otro y, a la vez, que no sufran ningún daño.

El archivo corriente

Se puede entender por Archivo Corriente la secretaría de la escuela, pues es allí que gran parte de la documentación es recibida, generada y conservada. Un ejemplo que prueba que la secretaría es responsable de los documentos en la escuela es cuando necesitamos de nuestro historial escolar. ¿Qué es lo primero que buscamos? Buscamos el empleado o la empleada de la secretaría de la Escuela, quien comunica al director cuando encuentra el documento solicitado y si éste puede ser autorizado para extenderlo. Además de esa tarea, es la secretaría que administra y produce los documentos de actividades medias en la escuela, siendo la responsable de gran parte del trámite documental.

Es una realidad que en una escuela nueva todos los documentos en fase corriente pueden ser administrados en un único lugar. Sin embargo, existen escuelas en que, debido a un volumen de documentos en esa fase, las responsabilidades son subdivididas.

La Escuela Técnica Estatal Getúlio Vargas, por ejemplo, posee tres secretarías que funcionan en lugares diferentes. Cada una es responsable por una parte de la vida administrativa de la Escuela: servicios, empleados y lo académico. Sin embargo, tales secretarías continúan administrando los documentos en su génesis, su recepción y en su trámite, o sea, en su fase corriente.

En la Escuela de Aplicación existe solamente una secretaría que responde por todas las actividades. Los documentos en su poder son transferidos para el MEMO en dos épocas del año: en febrero, 
con el reinicio del año lectivo, y en julio, al final del receso escolar. Sin embargo, es en el primer momento que son transferidos grandes volúmenes de documentos, la mayoría son los que alcanzaron su plazo de prescripción y precaución. En el segundo momento, la mayoría de la documentación está encaminada a archivos de alumnos graduandos, traslados o desertores.

Con la organización del Centro de Memoria y del Archivo Permanente, la rutina de los funcionarios no sufrirá muchas alteraciones, ya que desde el momento que entienden la organización existente, se darán cuenta que es más fácil la protección de los nuevos documentos y el acceso a cualquier información existente en todo el acervo bajo custodia del MEMO.

Facilitar el acceso a la información a los empleados de la secretaría es uno de los objetivos de la investigación "La Historia de la Educación en riesgo: evaluación y eliminación de los documentos del archivo de la Escuela de Aplicación/ 1958-1985". Es por ese motivo, que desde octubre del 2001, con la ayuda de los empleados, se ha venido organizando la documentación existente en la escuela para responder las dudas de la comunidad escolar y de los investigadores.

Es en ese momento que se realiza la primera evaluación documental, la cual debe ser hecha por un equipo compuesto de representantes de funciones y actividades desarrolladas por la institución y debe ser presidida por representantes del SAUSP (Sistema de Archivos de la Universidad de Sao Paulo) e investigadores de Historia de la Educación de la Facultad de Educación.

El Archivo Intermediario

El Archivo Intermediario se encuentra en el ambiente amarillo y corresponde al conj unto de actividades que tienen por objetivos:

1. Conservar los documentos durante los plazos establecidos en la Tabla de Temporalidad;

2. Asegurar que los plazos de precaución sean respetados;

3. Realizar la eliminación de los documentos que, alcanzado el plazo de prescripción y precaución, fueron evaluados como documentos 
a ser eliminados. En ese momento, algunos datos de los documentos serán registrados en el Término de Eliminación. Un Edicto será fijado a los cuadros de aviso de la escuela, y es ahí, que serán eliminados por medio de un aparato triturador de papeles, y además, serán encaminados para el programa de Reciclaje de la USP;

4. Preparar documentos para ser encaminados al Archivo Permanente. Tales documentos serán saneados, acondicionados en carpetas de papel neutral y guardados en cajas "modelo delta" de archivo horizontal. Hecho esto, serán protegidos en el Archivo Permanente;

5. Confeccionar carpetas, chaquetas o cápsulas de papel neutral para el acondicionamiento de los documentos;

6. Preservar y mantener el orden de los materiales de consumo, cuidando para que no desaparezcan durante las actividades, es decir, que sean colocados en lugares diferentes;

7. Realizar pequeñas reposiciones;

8. Realizar la notación del documento según el plano de clasificación.

El Archivo Permanente

El Archivo Permanente se encuentra en el ambiente rojo y corresponde al conj unto de actividades que tienen por objetivos:

1. Garantizar la protección de los documentos en su fase histórica;

2. Registrar los documentos en el Banco de Datos;

3. Crear mapas de localización de las cajas en los estantes para facilitar el acceso;

4. Digitalizar imágenes en el caso que existan copias o generar nuevas imágenes por medio del uso de máquina fotográfica digital;

5. Generar y administrar negativos fotográficos o imágenes digitales;

6. Llevar al Archivo Intermediario documentos que necesiten pequeñas reposiciones o de nuevos acondicionamientos;

7. Apoyar al consultor en sus dudas;

8. Generar instrumentos en soporte papel o digital que faciliten la investigación;

9. Asegurar que los documentos reservados no sean consultados 
sin la debida autorización de los responsables. Dicha autorización deberá ser hecha por escrito;

10. Asegurar los créditos de auditoría y de publicación por medio de términos de responsabilidad, para que sean llenados de manera correcta por el investigador;

11. Garantizar el acceso rápido a la información;

12. Crear registro de investigadores;

13. Evitar que el documento salga del ambiente verde - de consulta;

14. Verificar si el documento que estaba siendo consultado está en orden antes de guardarlo, es decir, que no tenga garabatos ni recortes. Si se verifica y se prueban actos de mala fe, se deberá penalizar al responsable, prohibiendo su acceso a otros documentos. Esto debe ser hecho por el daño a un documento público, imposibilitando que otras personas lo consulten, lo cual es un crimen previsto por la ley.

El espacio de higienización y restauro

El espacio donde se encuentra el Archivo Intermediario también es utilizado para las actividades de higienización y pequeños restauros en los documentos. Todo el proceso será largamente explicado en el capítulo que trata de la continuidad de los trabajos hasta ahora desarrollados en el MEMO. Mientras tanto, algunas consideraciones al respecto de su establecimiento pueden ser hechas.

Al separar la sala de consultas de la sala de actividades técnicas para la protección y conservación de archivos, se pretendía localizar al alumno de la institución escolar en el espacio y facilitar que él pudiera percibir los papeles que se pueden desarrollar en el MEMO. Así, de acuerdo con la función asumida por el alumno, él conocería a priori dónde debería permanecer. Por ejemplo, si el alumno estuviera acompañado por sus colegas de clases y del profesor responsable, podrá ultrapasar el espacio de consulta, pues está en ese lugar con el propósito de auxiliar en la higienización y en el restauro de los documentos. Sin embargo, si estuviera solo, o con pocos amigos, sabrá que puede permanecer únicamente en el ambiente verde, o sea, en la sala de consulta y que deberá solicitar el documento para su investigación al responsable del acervo en aquel momento. 
Otra función del área de higienización y restauro es organizar los materiales de forma que garantice una fácil localización y evitar gastos innecesarios. El material debe quedar protegido en un único lugar próximo a ese espacio. De esta manera, el alumno será informado de que no podrá salir del local e ir a otros ambientes Ilevando materiales que estuviera utilizando en una de sus actividades.

\section{El espacio para investigaciones y exposiciones temporales}

El espacio destinado para la investigación debe respetar las consideraciones con respecto al espacio de higienización y restauro. Es en esta área que son hechos los trabaj os de sensibilización de la comunidad escolar por medio de exposiciones de trabajos, workshops y actividades con alumnos y practicantes.

Sin embargo, ese espacio se presta también para la exposición de piezas y fotografías que fueren encontradas junto a los documentos de soporte papel, o sea, dentro de las gavetas de los archivo de acero, dentro de las cajas o sobre los estantes en medio de los libros.

En el futuro se espera que sean hechas investigaciones con empleados y ex-alumnos para levantar la historia de cada pieza o fotografía que están en el acervo de la Escuela de Aplicación.

Para enriquecer el área de sensibilización del Centro de Memoria de la Escuela, se espera que ex-empleados, ex-alumnos e investigadores donen piezas significativas para el Centro, para memoria de la Escuela.

Los instrumentos de consulta del acervo

Los primeros instrumentos de investigación al acervo son: la Guía del Acervo, el Inventario Analítico, el Catálogo Selectivo de los documentos que pueden ser encontrados en otras instituciones y que están relacionados a la Escuela de Aplicación y el primer volumen del Caco (Catálogo de Correspondencias).

El inventario analítico de fuentes, bautizado como InventEA, o sea, 
Inventario Analítico de la Escuela de Aplicación, corresponde a la exposición de las informaciones relacionadas al conj unto documental que fue almacenado por la Escuela de Aplicación y que recibió el nombre de Archivo Muerto.

Ese instrumento fue elaborado para dar condiciones mínimas de recuperación de la información. La idea es tenerlo disponible en dos versiones: la primera, en soporte papel que quedará disponible en el MEMO para auxiliar en las investigaciones; la segunda, en soporte digital que se entregará exclusivamente al equipo de empleados de la secretaría con el objetivo de facilitar y agilizar la investigación al acervo con fines administrativos.

\section{Pistas importantes}

Cómo conservar la organización

Para conservar la organización establecida, son necesarios los siguientes cuidados:

1. Respete los ambientes de trabaj 0 , no desarrollando actividades fuera del lugar determinado. El cambio de materiales y documentos de sus respectivos lugares puede dificultar que sean encontrados después.

2. Utilice los instrumentos elaborados para las consultas y diríjase a la persona responsable del acervo siempre que necesite aclarar dudas. Estos instrumentos fueron creados justamente para facilitar la investigación al acervo. Se después de consultarlos, usted no encuentra la información que busca, utilice el instrumento fuentes relacionadas a la Escuela. Ese otro instrumento posee informaciones valiosas que podrán Ilevarlo a la institución y al documento deseado.

3. Al manej ar un documento, procure conservar el orden encontrado $y$, en hipótesis alguna, retire el documento del ambiente de consulta. De esa forma se facilita el trabajo de la persona que recogerá el material investigado y evita incidentes. 


\section{Cómo dar continuidad a la higienización y al acondicionamiento}

Tanto para realizar la higienización como el acondicionamiento, son necesarios algunos materiales. Tenga mucho cuidado en la compra de los materiales. Siempre que sea posible, escoja marcas, productos y proveedores ya conocidos.

En esta parte, se hace una lista de todo material necesario para la higienización y el acondicionamiento. Después, se enumerarán, paso a paso, los procedimientos para higienización y confección de los acondicionamientos.

La higienización

Para higienizar los documentos en soporte papel, se utilizan los siguientes materiales:

a) Brocha (tamaño 2 y $1 / 2$ )

b) Goma TK

c) Guantes quirúrgicos

d) Espátula

e) Tijera

f) Algodón (preferiblemente en forma de bolitas)

g) Extractor de grapas

h) Asta de algodón

Todo documento en soporte papel deberá ser higienizado al frente y al reverso (excepto las fotografías), tomándose el cuidado de hacerlo en una sola dirección. Las personas que estuvieran trabajando en el mismo ambiente deben tomar distancia unas de las otras o sentarse de manera individual. Ese cuidado es necesario para evitar que el sucio extraído de un documento sea transferido a otro.

Se recomienda que la mesa donde estén trabajando sea forrada con papel pardo grande, sujetado de las puntas. La higienización debe ser hecha de abajo para arriba, con el fin de acumular el sucio en un solo lugar y evitar que la persona se ensucie. Deje un cesto para basura próximo a la mesa para ir retirando la basura acumulada. 
A medida que se vaya haciendo la higienización del documento, preste mucha atención a la existencia de cintas adhesivas, adhesivos, clips, grapas - o cualquier otro tipo de metal - encontrados en el documento. Retírelos con un extractor de grapas (teniendo mucho cuidado de no dañar el documento) o con la espátula.

En caso que el documento esté muy sucio o amarillento, se recomienda que sea rallada la goma TK. Después que sea rallada, una parte será regada sobre cada hoja del documento, para que en movimientos circulares con las puntas de los dedos - ayude a retirar la mayor suciedad posible del documento.

Después de pasar la goma rallada sobre la hoja, utilice la brocha para sacar el polvillo de la goma que deberá ser colocado en la esquina superior de la mesa forrada con papel pardo. Terminada la higienización de todas las hoj as de los documentos, reserve el polvillo de la goma en un frasco transparente con tapadera, para reutilizarlo en la higienización del próximo documento. Si desea, ralle toda la goma y colóquela en un frasco transparente reservándola para la actividad de higienización; conforme se va utilizando colóquela en otro recipiente. Esa forma de guardar la goma ya utilizada permite que los alumnos vean si el documento está sucio por el color que va quedando en ella en cada reutilización. En promedio, un frasco pequeño trasparente lleno de goma rallada podrá ser utilizado para treinta documentos. Es claro, todo depende, de la cantidad de sucio que haya en la superficie del documento.

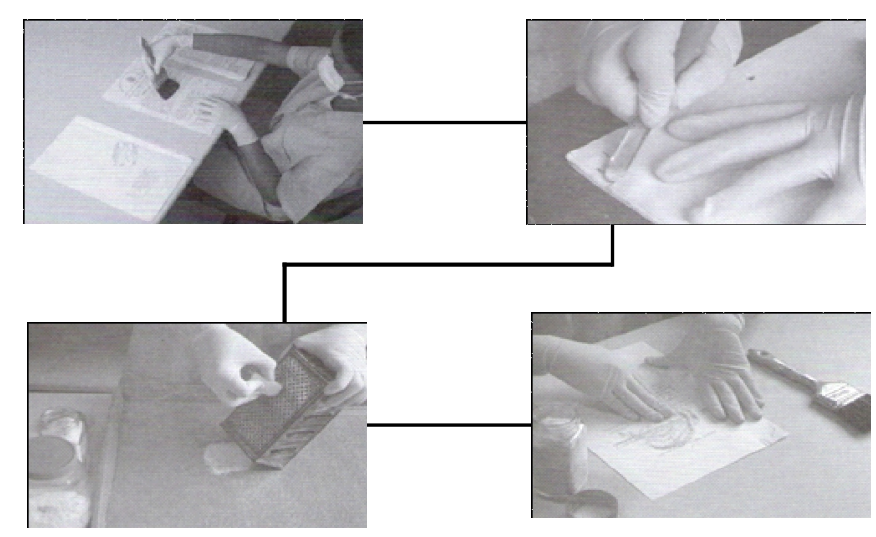


Ahora, las fotografías pasan por un proceso de higienización básica un poco diferente. En el lado de la imagen utilice el algodón en forma de bolitas y, en el otro, la brocha. Cuando sea necesario, utilice la goma rallada al reverso, como se explicó anteriormente para los documentos hechos en papel pergamino. Recuerde nunca pasar la goma rallada en el lado de la imagen, únicamente se debe utilizar en el otro lado.

Nuevamente, verifique si no hay ningún tipo de interferencia producida en el documento (clips, cintas adhesivas, adhesivos, etiquetas, etc.)

Así será realizada la higienización básica del documento. Es importante tener en mente que esos procedimientos son únicamente para la conservación y no solucionan problemas como manchas y pérdida de partes de los documentos. Cualquier otro procedimiento que tenga el objetivo de recuperar partes documentales es responsabilidad de los restauradores, siendo necesario guardar y proteger los documentos hasta que puedan ser enviados

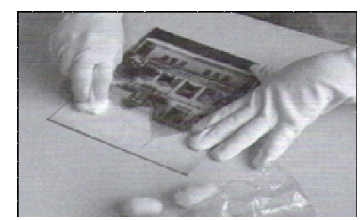
a esos especialistas.

\section{El acondicionamiento}

El acondicionamiento será subdividido en: acondicionamiento para documentos en soportes papel de modo general (inclusive papel periódico) y acondicionamiento para documentos en soporte de papel fotográfico.

Para acondicionar documentos en soporte papel, se utilizarán los siguientes materiales:
a) Papel filiset neutro $(68 \mathrm{~g} / \mathrm{m} 2)$
d) Portaminas $(0.7 \mathrm{~mm})$
b) Regla $(20 \mathrm{~cm})$
e) Goma
c) Estilete
f) Tijera 
Las carpetas serán confeccionadas a partir del formato de cada documento que se desee acondicionar. Sin embargo, como sabemos que gran parte de los documentos de una escuela es producida en papel de formato A4 y oficio, la mayoría de las carpetas están siendo hechas a partir del modelo que corresponde a las necesidades de esos soportes.

Pasos para la confección del modelo de carpetas-patrón:

1. Cada paquete de papel neutro corresponde a 250 hojas de $66 \mathrm{x}$ $96 \mathrm{~cm}$, con las cuales es posible confeccionar mil carpetas de ese modelo. Esos datos facilitan el control del material utilizado.

2. Cada hoja debe ser dividida en cuatro partes iguales. Los alumnos y profesores serán orientados para dividir la hoja al medio y, después, dividir cada parte, nuevamente por el medio, utilizando regla y estilete.

3. En seguida, cada hoja debe ser doblada suavemente por el medio, de manera que no se marque el papel.

4. Hecho eso, el profesor o el alumno deberá hacer un doblez de aproximadamente 2 centímetros del lado derecho de la parte del centro, y en su margen inferior, doblándolas firmemente de inmediato.

5. El papel deberá doblarse de nuevo por el medio, considerando los dobleces ya realizados. En este caso, el doblez de ser bien marcado, pues este será el medio definitivo de la carpeta.

6. Listos los dobleces hechos en la parte de adentro de la carpeta, quedará en la esquina inferior derecha, un doblez de papel que deberá ser retirado con el auxilio de una tijera.

7. Utilizando portaminas de $0.7 \mathrm{~mm}$, se harán dos rectángulos en la primera hoja de la carpeta. El primero tendrá $3 \times 4 \mathrm{~cm}$ y será hecho en la parte superior derecha de la hoja. El segundo deberá hacerse en el centro del papel y tendrá $11 \times 4 \mathrm{~cm}$. Con un pedazo de cartón se puede confeccionar un molde para evitar trazar las medidas en cada carpeta nueva. 


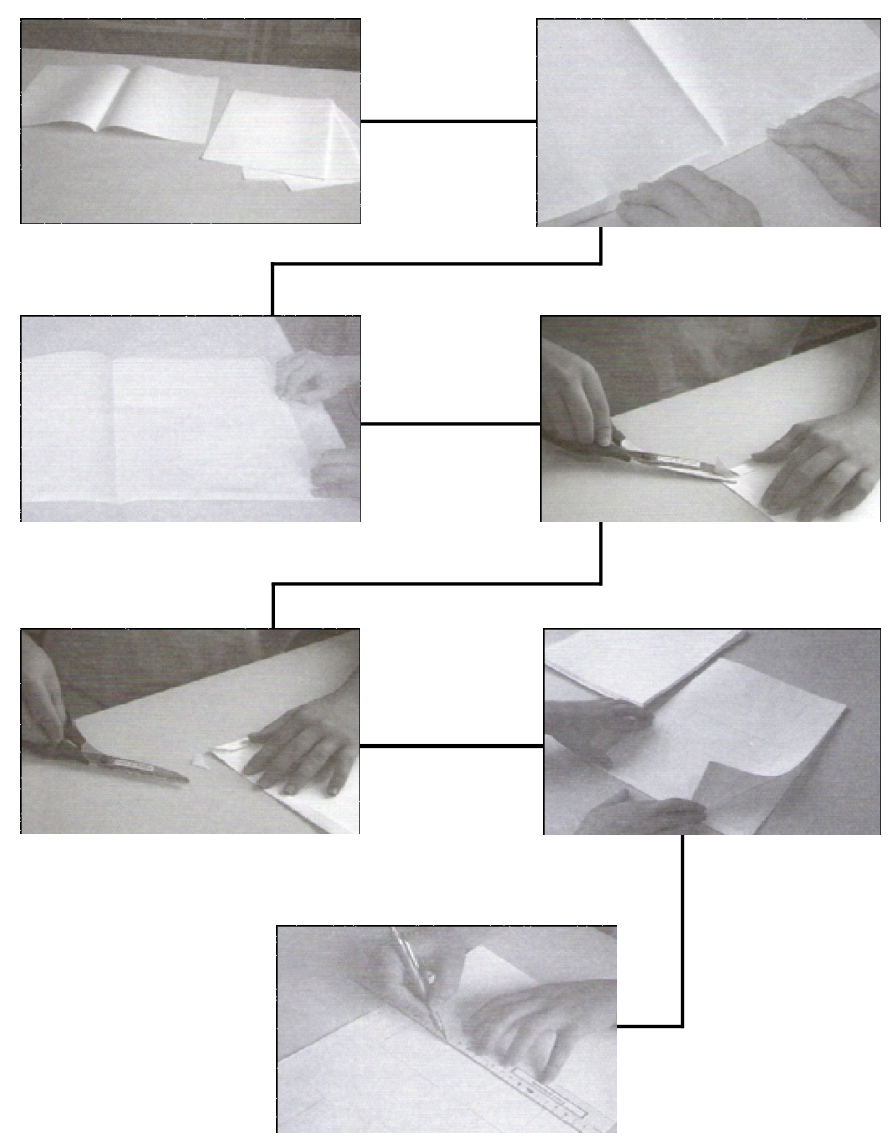

Así, la carpeta para acondicionamiento de documentos formato A4 y oficio está lista para utilizarse. Vale recordar que ese mismo modelo se puede adaptar para documentos de otros tamaños.

La importancia de los rectángulos hechos en la parte externa de la carpeta se discutirá en una fase posterior, referente a la identificación que el documento recibirá. Así, los campos trazados con lápiz carbón son fundamentales, ya que sirven para recuperar y tener acceso a la información del documento. 
Para acondicionar documentos en soporte papel fotográfico, se deberán utilizar los siguientes materiales:
a) Papel crescent
b) Película de poliéster
d) Papel Kizuki (papel japonés)
g) Tijera
h) Regla
e) Tiras de papel filiset neutro
i) Guillotina
f) Cinta de acetato
j) Lápiz portaminas
k) Goma para borrar

Pasos para la confección del modelo de carpetas para acondicionamiento de fotografías:

1. El primer paso es medir las fotografías, sumar a ellas $6 \mathrm{~cm} . \mathrm{y}$, con el portaminas, hacer un rectángulo con esas medidas sobre la hoja de papel crescent.

2. A continuación, con el auxilio del estilete y de la regla, recortar el papel crescent sobre los trazos de la medida.

3. Nuevamente, marcar $3 \mathrm{~cm}$. en cada uno de los 4 lados, formando un nuevo rectángulo.

4. Recortar sobre esta nueva línea. Usted tendrá una moldura cuadrada.

5. Después, rayar nuevamente sobre la hoja de papel crescent con la medida de la foto más $6 \mathrm{~cm}$.

6. Nuevamente se debe recortar el papel sobre el rectángulo hecho a partir de las medidas. Así, usted obtendrá otro rectángulo con las mismas medidas de la mol dura hecha con el primer rectángulo.

7. Unir la moldura con ese último rectángulo con auxilio de la cinta de acetato.

8. Recortar la película de poliéster con la misma medida de la foto, sin aumentar ningún centímetro.

9. Unir ese pedazo de película poliéster al reverso de la moldura con la cinta de acetato.

10. Hacer cantoneras, de preferencia con el papel filiset neutro utilizado en las carpetas hechas para acondicionar documentos en formato A4 y oficio. Cada cantonera debe tener $1 \mathrm{~cm}$. de ancho.

11. Pegar con pegamento neutro o cinta de acetato, 4 cantoneras en el segundo rectángulo hecho con papel crescent, las cuales deben quedar alineadas de acuerdo con las medidas de la fotografía. 
12. La fotografía podrá, entonces, ser presionada por las esquinas de cada cantonera.

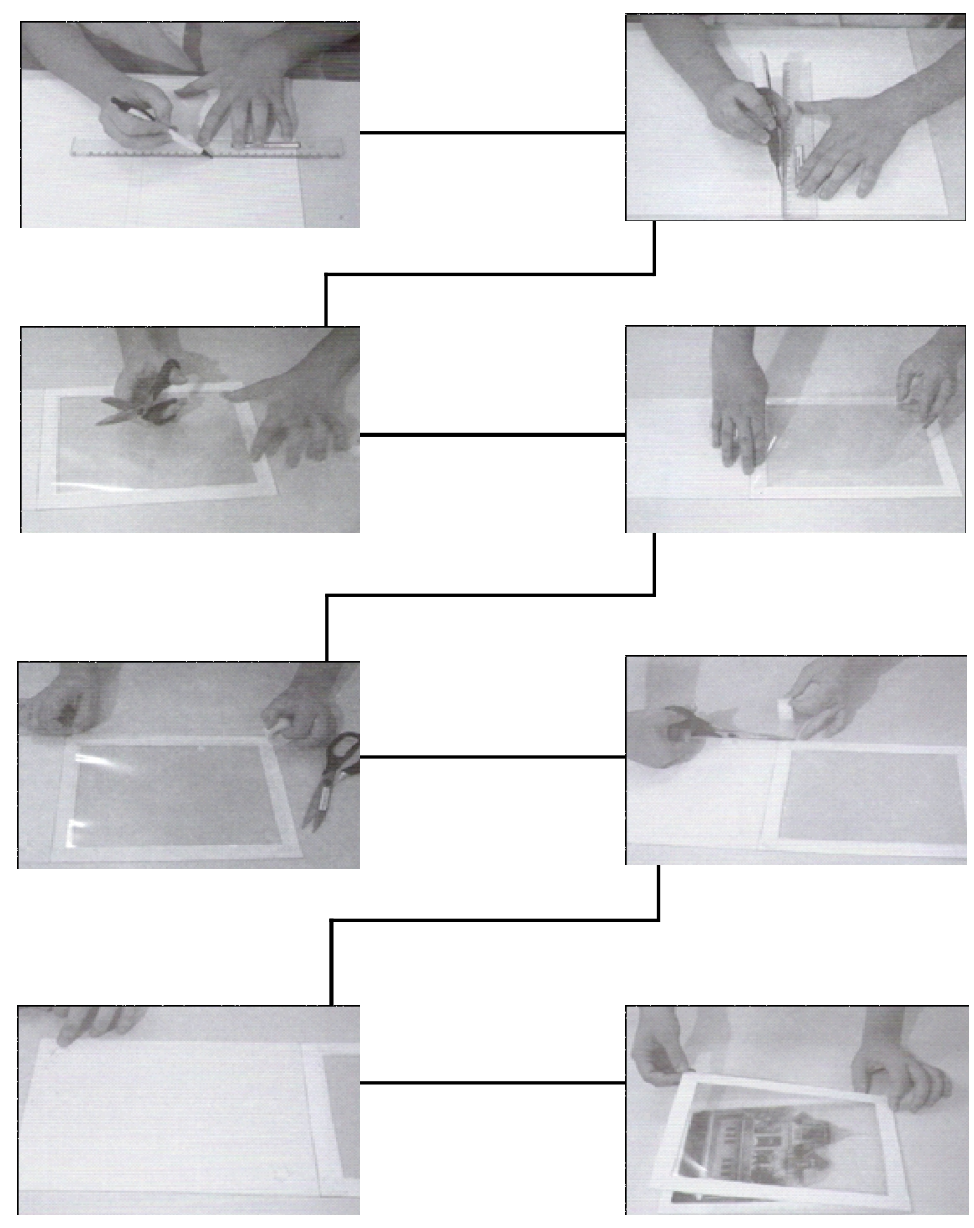

<Paradigma> - Revista de Investigación Educativa. Año 21. No. 34 
Este modelo de acondicionamiento, aunque sea más trabajoso, se escogió porque presenta muchas ventajas sobre el modelo de dobleces (con papel filiset) y el encapsulamiento, opciones bastante utilizadas en otras instituciones y que serán explicadas a continuación.

Una de las ventajas es la comprobada protección que este tipo de acondicionamiento proporciona contra el peso de otras fotos, cuando todas son guardadas dentro de la caja para archivar. Eso es porque, si colocamos una sobre otra, todas con la misma medida, el peso de acopio de las fotografías quedará concentrado en las respectivas molduras.

Otra ventaja es en cuanto al manejo. A diferencia del modelo de encapsulamiento, en el cual el investigador termina colocando su mano sobre la película de poliéster, único material que separa al consultor de la fotografía (corriendo el riesgo de rayarla), con este modelo, el consultor, inevitablemente, se apoyará en la moldura en vez de tocar la foto con los dedos.

Una tercera ventaja de este modelo es el hecho de ser de película (diferente del modelo hecho por medio de dobleces), lo que da sustento para transportar y evita dañar el documento cuando este fuere consultado o solicitado para exposición. Sin embargo, este modelo se destina solamente al acondicionamiento de fotografías originales, siendo sus copias guardadas en carpetas de dobleces de papel neutro.

Vea a continuación los pasos para la confección de carpetas de dobleces de papel neutro:

1. Medir la fotografía. Después, aumentar $2 \mathrm{~cm}$. a su medida.

2. Recortar la hoja de papel neutro con esas medidas.

3. Doblar sus puntas para adentro hasta que ellas se encuentren. Haga dobleces bien firmes.

4. Después, colocar la fotografía dentro del cuadro, cerrando con las puntas que ya fueron dobladas. 


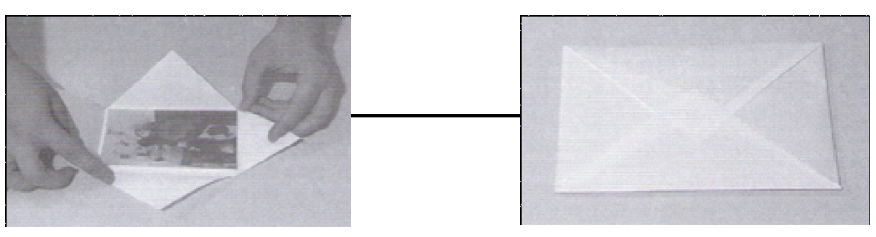

Ese es el acondicionamiento más fácil y también bastante convencional.

Otro tipo de acondicionamiento muy utilizado para fotografías es el encapsulamiento. Vea a continuación los pasos para la confección de carpetas de encapsulamiento:

1. Rayar en un pedazo de papel crescent la medida de las fotografías aumentadas de $1 \mathrm{~cm}$. Solamente del lado derecho deberán ser aumentados $5 \mathrm{~cm}$.

2. Después, recortar el papel crescent sobre sus líneas trazadas.

3. Rayar nuevamente las medidas de la fotografía aumentadas de $1 \mathrm{~cm}$. Sólo que esta vez tendrá que rayar en la película de poliéster con el auxilio de un pincel atómico de punta fina. No olvide de limpiar la película con algodón después de cortarla. Recuerde que esta vez no será necesario

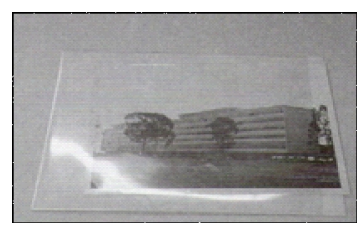
el aumento de $5 \mathrm{~cm}$. del lado derecho.

4. Después, usando cinta mágica o neutra, prenda la película de poliéster sobre el papel neutro. Del lado derecho sobrarán $5 \mathrm{~cm}$. de papel neutro y también una abertura para la introducción de la fotografía.

\section{Cuidados con los ambientes}

Los ambientes donde están guardados los documentos y donde serán manejados deben recibir una serie de cuidados.

El primer cuidado está relacionado a la forma de mantener limpios los espacios y los utensilios. En el MEMO, durante el último año, siempre que es posible, conversamos con el personal de la limpieza, mostrando una serie de maneras para limpiar el espacio sin dañar 
la documentación y, al mismo tiempo, facilitando el trabajo de los responsables.

Para la limpieza del piso se recomienda que no se empleen trapos muy mojados. El mismo procedimiento fue adoptado para estantes de libros, archivos de acero, mesas y sillas. Se debe usar regularmente una franela seca para retirar el polvo, ya que la humedad propicia el medio para la propagación de agentes perjudiciales al documento. Los estantes, las cajas de archivo y el exterior de los volúmenes deben limpiarse antes de su manejo. Se debe tener en cuenta lo anterior para prevenir que el sucio y la contaminación sean transferidos para el documento durante la manipulación.

Para eliminar la humedad relativa del aire, utilizamos un aparato deshumidificador en el MEMO. Sin embargo, después de los primeros seis meses, pudimos percibir que su uso próximo a la sala de consultas o al archivo permanente no era necesario, ya que el Centro está localizado en el segundo piso del edificio y posee grandes ventanas de vidrio, lo que facilita el calentamiento de esos dos espacios. Verificamos, entonces, que, de toda el área del MEMO, la más húmeda es el área de higienización y restauro, debido a la proximidad con el baño. De esa forma, el deshumidificador fue transferido para allá.

Es necesario tener mucho cuidado con el uso de deshumidificadores en el ambiente donde está el acervo. En caso que el deshumidificador posea depósito para la acumulación de agua, es necesario que los responsables del acervo se certifiquen que el depósito sea diariamente vaciado para evitar filtraciones en el área del acervo.

En días húmedos y lluviosos, se debe evitar abrir las ventanas y transportar paraguas o capas moj adas en los ambientes; si es posible, se deben dejar en el baño. En días más secos de lo normal no se deben abrir las ventanas. En los ambientes más secos se puede colocar una palangana con agua en la esquina de la sala. Sin embargo, esa medida se debe utilizar como solución inmediata, en la falta de un humidificador, es necesario duplicar a vigilancia sobre el acervo.

Es muy importante evitar la presencia de plantas en el ambiente. 
Las salas de consulta y de higienización poseen ventiladores para refrescar el ambiente. En cuanto a los lavatorios de los baños, uno está sellado, pues el espacio funciona como reserva técnica, y el otro es frecuentemente inspeccionado por alguien del MEMO para certificarse de que el grifo está bien cerrado y la puerta recostada.

La exposición de los documentos (principalmente) a la luz es evitada. Todas las ventanas poseen cortinas largas que están permanentemente cerradas. La luz artificial, incluso en la sala de consulta, es evitada. Siempre que sea posible apague las luces en los ambientes.

Variaciones de temperatura y humedad acarrean el "encogimiento" - la "dilatación" del documento. La humedad provoca el deterioro biológico, o sea, el surgimiento de moho. La reacción de las fotografías, en especial, a los contaminantes ambientales puede ser percibida por el cambio en su color, que pasa a quedar amarillento. 
Iomar Barbosa Zaia

\section{Referencias Bibliográfícas}

CAMARGO, Ana María \& BELLOTTO, Heloisa Liberalli. Diccionario de terminología archivística. Sao Paulo, Asociación de los Archivistas Brasileños/ Secretaría de Cultura, 1996.

CASSARES, Norma Cianflone \& MOI, Cláudia. Cómo hacer conservación preventiva en archivos y bibliotecas. Sao Paulo, Archivo del Estado, 2000 (Proyecto Cómo hacer no 5).

FILIPPI, Patrícia de, LIMA, Solange Ferraz de \& CARVALHO, Vânia Carneiro de. Cómo tratar colecciones de fotografía. 2. Ed. Sao Paulo, Archivo del Estado, 2002 (Proyecto Cómo hacer no 4).

FONSECA, Edson Nery da. Conservación de bibliotecas y archivos en regiones tropicales. Presentación de Gilberto Freyre. Brasilia, Ediciones ABDF, 1975.

GOMES, Sônia de Conti. Técnicas alternativas de conservación: un manual de procedimientos para manejo, reparos y reposición de libros, folletos y mapas. Belo Horizonte, Editora de la UFMG, 1992.

PALETTA, Fátima Aparecida Colombo. Manual de higienización de libros y documentos encuadernados. Sao Paulo, Hucitec, 2004.

SISTEMA DE ARCHIVOS DE LA UNIVERSIDAD DE SAO PAULO. Manual de conservación preventiva de documentos. Sao Paulo, Edusp, 2005.

THE BRITISH LIBRARY. National Preservation Office. Preservación de documentos: métodos y práctica de protección. Traducción de Zeny Duarte de Miranda Magalhães dos Santos, presentación de Robert Howes. Salvador, EDUFBA, 2000. 
El acervo escolar: manual de organización y cuidados básicos

\section{Algunos sitios Web}

www.cpba. net

Proyecto Conservación Preventiva en Bibliotecas y Archivos. Acceso: 22 de mayo del 2006.

www. funarte.gov.br

Fundación Nacional de Arte. Centro de Conservación y Preservación Fotográfica. Acceso: 6 de abril del 2006.

www. iphan. org. br

Instituto del Patrimonio Histórico y Artístico Nacional.

Acceso: 2 de febrero del 2006.

www.fphesp.org

Fundación Patrimonio Histórico de la Energía de Sao Paulo. Acceso realizado: el 22 de mayo del 2006.

www. arquivoestado.sp.gov.br 2006.

Archivo del Estado de Sao Paulo. Acceso: 22 de mayo del

www.aber.org.br

Asociación Brasileña de Encuadernación y Restauro. Acceso: 22 de mayo del 2006. 